\section{In Vitro Germination and Dormancy Responses of Hydrangea macrophylla and Hydrangea paniculata Seeds to Ethyl Methane Sulfonate and Cold Treatment}

\author{
Stephen Patrick Greer ${ }^{1}$ and Timothy A. Rinehart \\ USDA-ARS, Southern Horticultural Laboratory, Southern Horticultural \\ Laboratory, 810 Highway 26 West, Poplarville, MS 39470
}

Additional index words. stratification, seed physiology, alkylating agents, mutation breeding, Trichloro-s-triazinetrione (Trichlor), 2,3,5-triphenyl-2H-tetrazolium chloride (TTC), ImageJ

Abstract. To determine the optimal conditions for mutagenesis of Hydrangea macrophylla (Thunb.) Ser. and Hydrangea paniculata Siebold, cold-treated and untreated seed from representative cultivars were exposed to $0.5 \%, 2.5 \%$, and $5.0 \%$ ethyl methane sulfonate (EMS). Most untreated $\boldsymbol{H}$. macrophylla seed exposed to $2.5 \%$ and $5.0 \%$ EMS had substantially lower germination percentages. $H$. paniculata seed germination percentages did not differ from controls until EMS concentrations reached $5.0 \%$. Cold treatment of $\boldsymbol{H}$. macrophylla and $\boldsymbol{H}$. paniculata seed made germination more tolerant to all concentrations of EMS tested and increased germination of most $\boldsymbol{H}$. macrophylla cultivars when compared with lower dosages. Germination of cold-treated seed from $H$. paniculata cultivars rose substantially above control levels even at the highest dosages. For the most part, we observed more nondormant seed, or seed available for germination, but less viability with increasing EMS dosage in untreated Hydrangea $\mathrm{L}$. seed versus controls. In contrast, cold-treated seed displayed higher levels of mutagen tolerance and nondormancy versus controls when exposed to these same doses of EMS.

Ethyl methane sulfonate (EMS) is a mutagen that chemically alters DNA through random reaction and modification of oxygen present in nucleotide bases (such as the $\mathrm{O6}$ of guanine and $\mathrm{O} 4$ of thymine) as well as in DNA phosphate groups (Sega, 1984). This, in turn, causes mismatched base pairing to occur. Although EMS is capable of causing double strand breakage in higher organisms (Hoffmann, 1980; Sega, 1984), almost all erroneous DNA repair of EMS damage in plant genomes yields transition mutations with the original $\mathrm{G} / \mathrm{C}$ pair being replaced by an $A / T$ pair (Greene et al., 2003). In spite of the production of similar mutation types during EMS exposure, the rates of chemical mutagenesis are known to differ significantly among plant species (Filkowski et al., 2004; van Harten, 1998; Waugh et al., 2006) and even within species (Henikoff and Comai, 2003). As a result, proper application of chemical mutagens like EMS often requires protocols to be independently established for targeted species, cultivars, and ecotypes.

Alkylating agents like EMS have been used to increase allelic diversity in plants and generate breeding lines (see http://wwwmvd.iaea.org for a current list of reported mutant varieties) for more than 4 decades

Received for publication 6 Oct. 2008. Accepted for publication 12 Feb. 2009.

${ }^{1}$ To whom reprint requests should be addressed; e-mail stephen.greer@ars.usda.gov. germination. We defined viability in terms of whether a seed was alive or dead, dormancy as a physiological state in which the germination processes of viable seed are inhibited, and germination as the appearance of a radicle from the seed of any size.

\section{Materials and Methods}

Seed collection. Commercial cultivars of H. macrophylla subsp. serrata Makino 'Blue Bird', 'Beni Gaku', 'Intermedia', 'Omacha', and H. macrophylla subsp. macrophylla 'Coerulea', 'Lady in Red', 'Nikko Blue', 'Seafoam', 'Tokyo Delight', and 'Veitchii' were obtained from Amethyst Hill Nursery (Aurora, OR) and were grown outside under $50 \%$ shade at the USDA-ARS Southern Horticultural Laboratory in Poplarville, MS, or at the Mississippi State Truck Crops Branch Experiment Station in Crystal Springs, MS. Whole infructescences from these open-pollinated $H$. macrophylla plants were collected in October and November of 2007 and seed were harvested by crushing seed pods manually between fingers or mechanically grinding them with the aid of an electric food chopper (Black and Decker Corp., Towson, MD). After harvesting, seed were initially separated from larger particulates by repeated passage through a tea strainer. Seeds and smaller particulates were then rolled around on loose paper to separate seed from the finer particulates, which clung more fastidiously to the paper. Open-pollinated seed from $H$. paniculata 'Big Ben' and 'Pink Diamond' were obtained from Dr. Sandy Reed at the Tennessee State University Nursery Crop Research Station in McMinnville, TN. Dried whole infructescences were removed and shaken to release seed from seed pods. Seeds obtained from these plants were large and relatively clean so no further processing was needed. All collected seed were stored at $24{ }^{\circ} \mathrm{C}$ in ambient relative humidity, ranging from $55 \%$ to $70 \%$, until their use in experiments.

Cold treatment, chemical treatment, and sterilization of seed. Seed used in experimental studies were first aliquoted into polypropylene microtubes and cold-treated at $4{ }^{\circ} \mathrm{C}$ for 6 weeks under dry conditions. Untreated seed used in this study were kept under identical dry conditions at $24{ }^{\circ} \mathrm{C}$. One day before plating, all seed were imbibed with agitation in solution containing $300 \mathrm{ppm}$ of Trichlor (Trichloro-s-triazinetrione; Pool Time Products, Buford, GA), 1300 ppm gibberellic acid $\left(\mathrm{GA}_{3}\right.$; PhytoTechnology Laboratories, Shawnee Mission, KS), and $1000 \mathrm{ppm} \mathrm{KNO}_{3}$ (Acros Organics, Morris Plains, NJ) for $24 \mathrm{~h}$. For seed used as controls, the resultant supernatant (often containing a mixture of dissolved dirt and washed off debris) was decanted and a second wash of 2500 ppm Trichlor was applied to seed with agitation for 10 to $15 \mathrm{~min}$ and subsequently decanted. For seed that were chemically mutagenized, the initial supernatant was decanted and a solution of $0.1 \mathrm{M}$ potassium phosphate buffer (Sigma-Aldrich, St. Louis, 
MO), pH 7.0, containing $0.5 \%, 2.5 \%$, or $5.0 \%$ EMS (Sigma-Aldrich) was added to respective tubes. These tubes were then agitated at $24{ }^{\circ} \mathrm{C}$ for $3 \mathrm{~h}$ after which the EMS solution was decanted into $50 \%$ sodium thiosulfate. Seed in each tube were then briefly suspended in $500 \mathrm{ppm}$ Trichlor and the resultant wash decanted again into $50 \%$ sodium thiosulfate. A final wash of $2500 \mathrm{ppm}$ Trichlor was applied to seed with agitation for 10 to 15 min and then decanted into 50\% sodium thiosulfate. After final washes with 2500 ppm Trichlor, all respective seed, controls as well as seed exposed to EMS, were suspended in a solution containing appropriate volumes of $0.2 \%$ agar and $1000 \mathrm{ppm}$ Trichlor. One hundred to 500 sterilized seeds were sown on plates and three randomized replicate plates were used per treatment. Incubations of seed were done on solid media within $100 \times 15-\mathrm{mm}$ petri dishes (VWR International, West Chester, PA) that contained $0.5 \%$ Phytoblend agar (Caisson Laboratories, North Logan, UT), 0.2\% Plant Preservative Mixture (PPM; Plant Cell Technology, Inc., Washington, DC), $0.5 \times$ Gamborgs B5 + vitamins (PhytoTechnology Laboratories; Gamborg et al., 1968), and 130 ppm GA 3 (final concentration).

Light conditions for experimental treatments. Plated seed were placed under 40-W Sylvania Gro-Lux lights (Danvers, MA) for $21 \mathrm{~d}$ at $24{ }^{\circ} \mathrm{C}$ with red cellophane completely covering the lights; approximate visible wavelength emission ranged from 610 to $750 \mathrm{~nm}$ as measured by a Perkin Elmer (Waltham, MA) Lambda3B spectrophotometer. Photosynthetic photon flux was measured with an Apogee QMSW-5S quantum meter (Apogee Instruments Inc., Logan, UT) and was $15 \mu \mathrm{mol} \cdot \mathrm{m}^{-2} \cdot \mathrm{s}^{-1}$ levels for lights covered with red cellophane. Illuminance, as measured by a Control Company Model \#4332 light meter (Control Company, Friendswood, TX), was $\approx 650 \mathrm{~lx}$ for red (cellophane-covered) light reaching the plates. For all experiments, seed were subject to a 16:8 light:dark cycle.

Seed staining and image acquisition. After $21 \mathrm{~d}$ of incubation, total numbers of germinated seed on plate were manually quantified with the aid of an Olympus CO11 Stereo microscope (Olympus America Inc., Center Valley, PA). Seed were counted as germinated if the seedcoat had been clearly broken and a radicle of any size had emerged. After germination counts were recorded for each plate, $10 \mathrm{~mL}$ of freshly made $0.2 \%$ 2,3,5-triphenyl-2H-tetrazolium chloride (TTC; Alfa Aesar, Ward Hill, MA) was added to each plate (enough to completely cover and submerge all the remaining seed) and each plate was immediately put in complete darkness for $48 \mathrm{~h}$. Each plate was then photographed at 7.1 megapixel resolution (Fig. 1) using optimal ambient light conditions with a Canon Powershot A560 digital camera (Canon USA Inc., Lake Success, NY).

Image processing and seed quantification. Digital image of plates were processed with the aid of Picasa software (Google Inc.,
Mountain View, CA) and ImageJ (Abramoff et al., 2004) to count the total number of seeds on a plate and the number of seeds stained red. In short, images were first tuned in Picasa by turning highlights up to $100 \%$, shadows up to $50 \%$, and adjusting fill light until all the contaminating artifacts of the petri dish in the picture were minimized. This resultant image, which shows primarily only seed and some contaminating particulate matter, was then split into three separate but different image reproductions with the aid of Picasa's filtered black and white effect feature. To generate the first reproduction, green color was filtered from the image. In this image, all seed (dormant and nondormant) as well as particulate matter were darkened and visually detectable. A second image reproduction was generated by filtering all the green and yellow color out of the initial colored image. In this image, germinated, dormant, or dead seed were no longer visually detectable, and only nondormant (red) seed and contaminating particles were visible. A third image reproduction was generated by filtering all the green, yellow, and red color out of the initial image. The only visible constituents of this resulting image were contaminating particles present within the seed mixture, most often dirt or pieces of seed pods.

ImageJ's "Analyze Particles" feature was used to quantify the number of seed-sized particles in each image. We calculated that the average pixelized area of $H$. macrophylla seeds measured $\approx 150$ to 200 pixels $(\approx 0.25$ to $0.40 \mathrm{~mm}^{2}$ ) and the pixelized average area of H. paniculata seeds ranged from 350 to 900 pixels $\left(\approx 0.65\right.$ to $\left.1.0 \mathrm{~mm}^{2}\right)$. Using identical binary threshold sensitivities for each image, we quantified $H$. macrophylla or $H$. paniculata seed by slightly expanding pixel area cutoff parameters so that particles ranging from 50 to 300 pixels were tabulated on $H$. macrophylla plate images and a range of 300 to 1200 pixels was used to tabulate $H$. paniculata. The number of particles identified by ImageJ from the first reproduction of each plate image included all seed (dormant and nondormant) as well as the contaminating particulates, which were visible. The number of particles counted in the second reproduction of a plate image (showing particulates and TTC-stained seed) was subtracted from the first yielding a total number of dead or dormant (yellow) seed that were present initially on a sample plate. Subtracting the number of particles in the third image, which contained only contaminant particles, from the particles counted in the second image yielded the total number of red (viable and nondormant) seed that were present on each sample plate. Thus, the total number of yellow and unstained (dormant or dead) seeds for each sample was calculated subtracting the number of particles in image 2 from image 1 , and the total number of TTCstained, nondormant seeds for each sample was calculated subtracting the number of particles in image 3 from the particles counted in image 2 .

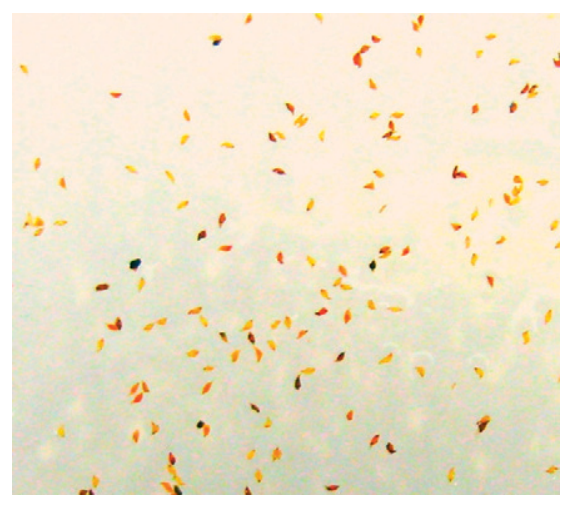

Fig. 1. Hydrangea seed stained with 2,3,5-triphenyl-2H-tetrazolium chloride (TTC) for 48 h. Hydrangea seed were grown on plated media, stained with TTC, and photographed to generate a 7-megapixel image. This image was further processed to count TTC-stained (red) seed, unstained (yellow) seed, and other debris (black).

Calculations and statistics. Percentage of nondormant seed for each plate was calculated by adding the numbers of germinated and red seed and dividing the sum by the total of red $(\mathrm{R})$, yellow $(\mathrm{Y})$, and germinated $(\mathrm{G})$ seed: $(G+R) /(G+R+Y)$. Percent germination of nondormant seed on a plate was calculated by dividing the number of germinated seed by the sum of the germinated seed and the red seed on a plate: $\mathrm{G} /(\mathrm{G}+\mathrm{R})$. The germination index, or total germination expected per amount of total seed, was calculated by multiplying percent nondormant seed by percent germinated, nondormant seed.

Univariate analysis of variance (ANOVA, $\alpha=0.05)$ and Ryan-Einot-Gabriel-Welsch Range post hoc tests $(\alpha=0.05)$ were conducted with SPSS software (SPSS Inc., Chicago, IL) to analyze significance. When transformation was required to meet assumptions of normality or equal variances, data sets were Tukey normal scored using the formula $(r-1 / 3) /(w+1 / 3)$, where $r$ is the rank and $\mathrm{w}$ is the sum of the case weights (Tukey, 1962). Eta-square $\left(\eta^{2}\right)$ and Type II error statistics $(\beta)$ statistics were also calculated for each ANOVA to verify variance contribution and the power of our statistical tests (Sokal and Rohlf, 1995).

\section{Results}

Within cultivars, EMS treatments caused differences in percent nondormant seed (Table 1), percent germination of nondormant seed (Table 2), and total germination index (Table 3 ). In most cultivars, increasing EMS exposure caused declines in the amount nondormant seed present, but as a trend, the severity of these declines was lessened by cold treatment. A significant decrease in percentage of nondormant seed was observed for $5.0 \%$ EMS exposures of 'Coerulea', 'Veitchii', and 'Blue Bird' untreated seed. Similar trends of declining percent nondormancy were observed in the untreated seed of 
Table 1. Percent nondormant seed for cold-treated and untreated seed exposed to ethyl methane sulfonate (EMS) at three concentrations. ${ }^{\mathrm{z}}$

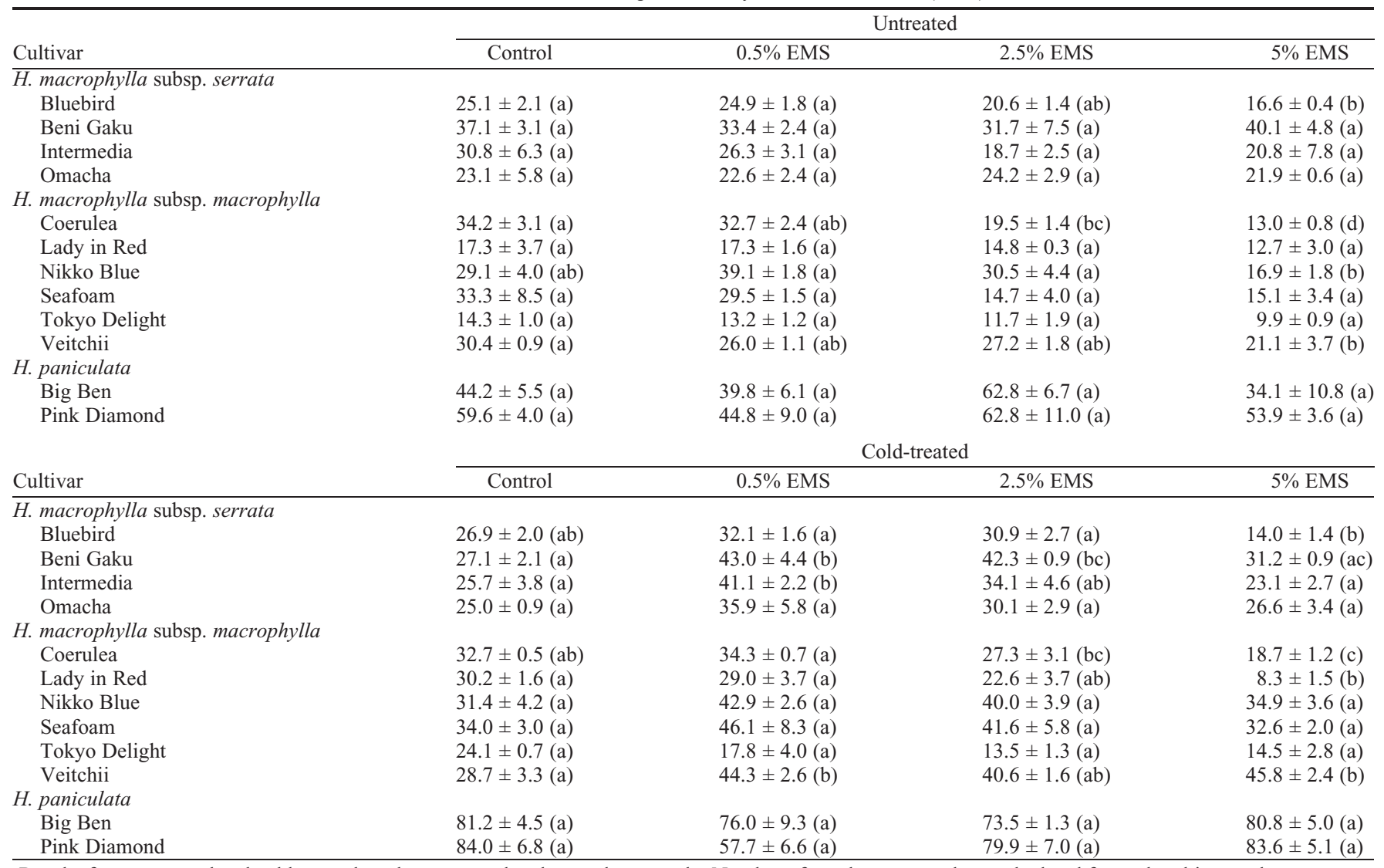

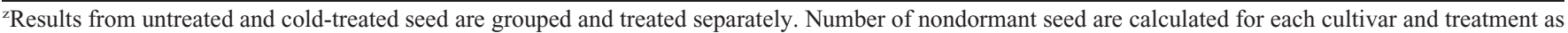
mean percentage $\pm \operatorname{SE}(n=3)$. Letters in parentheses are the results of Ryan-Einot-Gabriel-Welsch Range post hoc analyses $(P<0.05)$ from univariate analysis of variance $(\alpha=0.05)$ analyzing the range effects of dosage within cultivar. Thus, starting with the controls, different letters within a row indicate that respective percent nondormant seed values differ significantly as a result of EMS exposure.

all other cultivars except 'Beni Gaku'. In contrast, 5.0\% EMS exposure only elicited significant declines in percentage of nondormancy of cold-treated 'Lady in Red' and 'Coerulea' seed and general trends for percent of nondormancy decline did not exist in most other cold-treated cultivars. Five percent EMS exposure actually increased percentage of nondormancy of cold-treated 'Veitchii' seed.

Significant declines in percent germination of nondormant seed caused by $5.0 \%$ EMS treatments were present in untreated 'Blue Bird', 'Coerulea', 'Seafoam', 'Omacha', 'Tokyo Delight', and 'Big Ben', but were not present in cold-treated seed from these same cultivars. Similar trends were seen in all of our Hydrangea cultivars except for 'Veitchii' and 'Lady in Red', which exhibited substantial declines of percent germination for nondormant seed in both untreated and cold-treated seed exposed to $5.0 \%$ EMS. Germination percentage for nondormant cold-treated 'Omacha' seed actually increased significantly in response to 5.0\% EMS exposure.

Initial changes in percent nondormant seed and percent germination for nondormant seed had cumulative effects on germination indices. In untreated seed, significant total germination decreases occurred between controls and 5.0\% EMS treatment in all cultivars except 'Omacha' and 'Pink Dia- mond' (Table 3). Conversely, a significant decrease in the total germination of coldtreated seed in response to 5.0\% EMS treatment only occurred in 'Lady in Red' and 'Tokyo Delight'. Also of note, 5.0\% EMS treatment actually elicited sizeable germination index increases in both $H$. paniculata cultivars.

Lower exposures to EMS caused changes in percent nondormant seed, percent germination of nondormant seed, and total germination in many cultivars. The lowest EMS exposure $(0.5 \%)$ caused significant increases in the percentage of nondormancy observed in cold-treated 'Beni Gaku', 'Intermedia', and 'Veitchii' seed. Similar trends for increase were also observed in cold-treated 'Blue Bird', 'Seafoam', and 'Omacha' seed, but no such trends for increase were observed to be exclusive to untreated seed. In general, exposure of seed to low levels of EMS caused a trend for increased percent germination of nondormant seed, which was not limited to whether the seed were cold-treated. The notable exception was 'Big Ben' whose predisposition to not germinate as a result of cold treatment (Table 2, untreated controls versus cold-treated controls) was altered significantly when exposed to $0.5 \%$ EMS. Cold treatment when combined with low doses of EMS caused cumulative significant increase (Table 3) in seed from 'Beni Gaku' and substantial increase of the germination indices in most of the other cultivars.

\section{Discussion}

The biochemical reduction of TTC relies on its catalyzation by dehydrogenases found in metabolically active tissue, particularly those dehydrogenases involved in the malic and alcohol systems (Smith, 1952). The final product of this reaction is formazan (Lakon, 1949), an insoluble red dye that then accumulates in metabolically active tissue. Normally, TTC staining is used to characterize and quantify seed that are viable; however, increases in nondormant seed percentages resulting from EMS treatment revealed that significant amounts of hydrangea seed do not initially stain, although they are undoubtedly viable because they are capable of staining later. Thus, in any particular pool of nonstained, untreated seed, there is a portion that are dormant. Despite the limitations of TTC staining in this study, the procedure still functioned as an effective tool to assay seed physiology changes occurring in response to treatments.

As a result of its respirative dependency, increased TTC staining as a result of treatment, either EMS or cold storage, most likely occurs as a result of seed reaching a distinct physiological stage or suitably high threshold 


\begin{tabular}{|c|c|c|c|c|}
\hline \multirow[b]{2}{*}{ Cultivar } & \multicolumn{4}{|c|}{ Untreated } \\
\hline & Control & $0.5 \%$ EMS & $2.5 \%$ EMS & $5 \%$ EMS \\
\hline \multicolumn{5}{|c|}{ H. macrophylla subsp. serrata } \\
\hline Bluebird & $53.7 \pm 7.4(\mathrm{a})$ & $52.1 \pm 3.8(\mathrm{a})$ & $29.8 \pm 2.2(\mathrm{ab})$ & $1.8 \pm 1.0(\mathrm{~b})$ \\
\hline Beni Gaku & $39.6 \pm 5.4(\mathrm{a})$ & $39.3 \pm 7.6(\mathrm{a})$ & $42.2 \pm 13.1(\mathrm{a})$ & $4.7 \pm 1.3(\mathrm{a})$ \\
\hline Intermedia & $32.6 \pm 5.8(\mathrm{a})$ & $32.9 \pm 8.6(\mathrm{a})$ & $29.3 \pm 3.3(\mathrm{a})$ & $5.1 \pm 2.3(\mathrm{a})$ \\
\hline Omacha & $10.8 \pm 3.0(\mathrm{a})$ & $15.6 \pm 2.5(\mathrm{a})$ & $8.3 \pm 2.1(\mathrm{ab})$ & $0.5 \pm 0.5(b)$ \\
\hline \multicolumn{5}{|c|}{ H. macrophylla subsp. macrophylla } \\
\hline Coerulea & $55.7 \pm 5.4(\mathrm{a})$ & $61.5 \pm 2.5(\mathrm{a})$ & $46.4 \pm 7.8(\mathrm{ab})$ & $1.2 \pm 1.2(\mathrm{~b})$ \\
\hline Lady in Red & $4.8 \pm 1.3(\mathrm{a})$ & $9.6 \pm 1.0(\mathrm{~b})$ & $0.0 \pm 0.0(\mathrm{c})$ & $0.0 \pm 0.0(\mathrm{c})$ \\
\hline Nikko Blue & $68.5 \pm 4.5(\mathrm{ab})$ & $79.9 \pm 2.5(\mathrm{a})$ & $66.6 \pm 6.1(\mathrm{ab})$ & $23.0 \pm 6.5(\mathrm{~b})$ \\
\hline Seafoam & $37.6 \pm 2.2(a)$ & $35.6 \pm 3.5(\mathrm{a})$ & $29.0 \pm 5.6(\mathrm{ab})$ & $0.0 \pm 0.0(\mathrm{~b})$ \\
\hline Tokyo Delight & $39.1 \pm 6.7$ (a) & $51.9 \pm 7.3(\mathrm{a})$ & $26.4 \pm 9.8(\mathrm{ab})$ & $2.8 \pm 1.6(\mathrm{~b})$ \\
\hline Veitchii & $49.8 \pm 1.4(\mathrm{a})$ & $51.3 \pm 6.5(\mathrm{a})$ & $43.9 \pm 3.9$ (a) & $22.6 \pm 8.9$ (a) \\
\hline \multicolumn{5}{|l|}{ H. paniculata } \\
\hline Big Ben & $65.4 \pm 7.1(\mathrm{a})$ & $65.1 \pm 1.5(\mathrm{a})$ & $43.5 \pm 5.9(\mathrm{ab})$ & $7.1 \pm 4.5(\mathrm{~b})$ \\
\hline \multirow[t]{2}{*}{ Pink Diamond } & $40.7 \pm 4.1$ (a) & $52.2 \pm 12.8(\mathrm{a})$ & $37.2 \pm 3.6(\mathrm{a})$ & $21.9 \pm 6.5(a)$ \\
\hline & \multicolumn{4}{|c|}{ Cold-treated } \\
\hline Cultivar & Control & $0.5 \%$ EMS & $2.5 \%$ EMS & $5 \%$ EMS \\
\hline \multicolumn{5}{|c|}{ H. macrophylla subsp. serrata } \\
\hline Bluebird & $53.8 \pm 2.0(\mathrm{a})$ & $42.2 \pm 3.7(\mathrm{a})$ & $53.0 \pm 9.9(\mathrm{a})$ & $33.4 \pm 4.2(\mathrm{a})$ \\
\hline Beni Gaku & $60.8 \pm 3.0(\mathrm{a})$ & $62.4 \pm 4.9(\mathrm{a})$ & $58.5 \pm 7.8(\mathrm{a})$ & $43.6 \pm 2.4(\mathrm{a})$ \\
\hline Intermedia & $45.7 \pm 7.3(\mathrm{a})$ & $29.4 \pm 0.9(\mathrm{a})$ & $37.5 \pm 7.4(\mathrm{a})$ & $36.5 \pm 5.0(\mathrm{a})$ \\
\hline Omacha & $20.0 \pm 3.2(\mathrm{a})$ & $25.5 \pm 2.6(\mathrm{ab})$ & $25.4 \pm 3.0(\mathrm{ab})$ & $33.6 \pm 2.1(\mathrm{~b})$ \\
\hline \multicolumn{5}{|c|}{ H. macrophylla subsp. macrophylla } \\
\hline Coerulea & $56.4 \pm 1.3(\mathrm{a})$ & $65.7 \pm 5.3(\mathrm{a})$ & $66.1 \pm 4.0(\mathrm{a})$ & $40.9 \pm 12.4(\mathrm{a})$ \\
\hline Lady in Red & $32.0 \pm 6.7(\mathrm{ab})$ & $36.4 \pm 2.7(\mathrm{a})$ & $13.3 \pm 0.4(\mathrm{bc})$ & $0.0 \pm 0.0(\mathrm{c})$ \\
\hline Nikko Blue & $58.5 \pm 3.1(\mathrm{a})$ & $62.2 \pm 2.6(\mathrm{a})$ & $61.9 \pm 1.8(\mathrm{a})$ & $61.3 \pm 3.2(\mathrm{a})$ \\
\hline Seafoam & $49.0 \pm 4.8(\mathrm{a})$ & $54.2 \pm 8.0(\mathrm{a})$ & $69.5 \pm 1.6(\mathrm{a})$ & $52.1 \pm 5.3(\mathrm{a})$ \\
\hline Tokyo Delight & $27.6 \pm 3.1(\mathrm{ab})$ & $38.5 \pm 5.9(\mathrm{a})$ & $31.4 \pm 1.9(\mathrm{a})$ & $16.4 \pm 1.5(\mathrm{~b})$ \\
\hline Veitchii & $64.9 \pm 7.1(\mathrm{a})$ & $53.3 \pm 4.2(\mathrm{ab})$ & $44.8 \pm 3.2(\mathrm{bc})$ & $34.1 \pm 1.9$ (c) \\
\hline \multicolumn{5}{|l|}{ H. paniculata } \\
\hline Big Ben & $44.5 \pm 5.2(\mathrm{a})$ & $63.3 \pm 1.8(b c)$ & $67.3 \pm 1.3(\mathrm{~b})$ & $57.7 \pm 2.2(\mathrm{ac})$ \\
\hline Pink Diamond & $37.3 \pm 7.1$ (a) & $47.2 \pm 3.7(\mathrm{a})$ & $61.0 \pm 6.4(\mathrm{a})$ & $50.2 \pm 9.8(\mathrm{a})$ \\
\hline
\end{tabular}

${ }^{\mathrm{z}}$ Results from untreated and cold-treated seed are grouped and treated separately. Germinated nondormant seed are calculated for each cultivar and treatment as mean percentage $\pm \mathrm{SE}(\mathrm{n}=3)$. Letters in parentheses are the results of Ryan-Einot-Gabriel-Welsch Range post hoc analyses $(P<0.05)$ from univariate analysis of variance $(\alpha=0.05)$ analyzing the range effects of dosage within cultivar. Thus, starting with the controls, different letters within row indicate that respective percent germination of nondormant seed values differ significantly as a result of EMS exposure.

of metabolic activity, which in turn produces substantial amounts or red color in the embryo. Progression to this stage indicates some level of heightened readiness for germination, or nondormancy, which is most likely the result of increased permeability of the seedcoat, the induction of processes needed for proliferation of the embryo, or both. Conversely, dormant seedcoat impermeability, metabolic quiescence, or both of these factors seemed to inhibit the formation of discernible color in our assays of hydrangea seed. Beside EMS and cold treatment, other individual factors such as treatment with exogenous thiourea or $\mathrm{GA}_{3}$, red or white light, and different light intensities have also been shown to influence Hydrangea seed dormancy (Greer et al., 2008).

In mature seed that is stored dry, embryonic cells are arrested at the G1 phase of the cell cycle. In this state, DNA is quite vulnerable to the deleterious effects of chemical mutagenesis. Although DNA repair is known to occur early on in germination (Tuteja et al., 2001), most plant-based studies to date have reported only deleterious effects of mutagens on M1 germination rates (e.g., Grant and Owens, 2001; Jabeen and Mirza, 2002; Jayakumar and Selvaraj, 2003). There have been a few exceptions in which authors have reported no significant decrease in seed germination resulting from application of
EMS (Alcantara et al., 1996), an increase in seed germination caused by low doses of EMS or ionizing radiation (Dhamayanthi and Reddy, 2002), and an increase in seed germination and respiration rates (cytochrome oxidase and amylase activity) correlated with exposure to low amounts of EMS (Xuebao, 1991). Our EMS dosage results for untreated $H$. macrophylla and H. paniculata seed emulate the prevailing trend of declining germination reported for the majority of other species, but our results for cold-treated seed parallel those previously mentioned by Dhamayanthi and Reddy (2002) and Xuebao (1991).

How cold treatment shortens dormancy and enhances germination in hydrangea seed exposed to EMS is still unclear. Plants are theorized to have developed adaptive responses to alkylating DNA damage, although specific mechanisms such as methylguanine methyltransferases have not yet been detected in plants (Britt, 1996). Recent studies have shown that the nucleotide and base excision repair pathways, which are also capable of repairing EMS damage, exist in plants and are most active in proliferating tissues (Kimura and Sakaguchi, 2006). Also, in certain plant species, unscheduled DNA synthesis and DNA damage repair is known to occur immediately after rehydration of dry seeds but before the normal S phase DNA replication (Vonarx et al., 1998). If this happens in hydrangea, it would help explain seed tolerance to mutagens, because attempts at DNA repair would occur before the proliferative effects of germination. Concentrations of EMS used in this study were high in comparison with most studies and were necessary to observe injury on imbibed, cold-treated seed and untreated seed of some cultivars. The need for high levels of EMS suggests that nucleotide and base excision repair may be active in these seed and may be stimulated by stratification cues, not just rehydration. Taking into account the known deleterious effects of EMS, it seems highly likely that increases in TTC-stained seed resulted from embryo DNA damage induction forcing a response from the embryo that is extricable from the process of germination. In fact, this increase can most likely be attributed to the previously posited respective increase in metabolic respiration that is needed to provide the energy for DNA repair processes, similar to that which has been reported to occur in EMS-treated rice seed (Xuebao, 1991).

Cold treatment of hydrangea seed before application of mutagenesis methods plays a role in overall response to treatment, but it remains to be seen whether confirmed mutants exist in greater numbers in cold-treated versus untreated seed. If cold treatment serves to stimulate DNA repair pathways, then perhaps 
Table 3. Germination indices of cold-treated and untreated seed exposed to ethyl methane sulfonate (EMS) at three concentrations. ${ }^{2}$

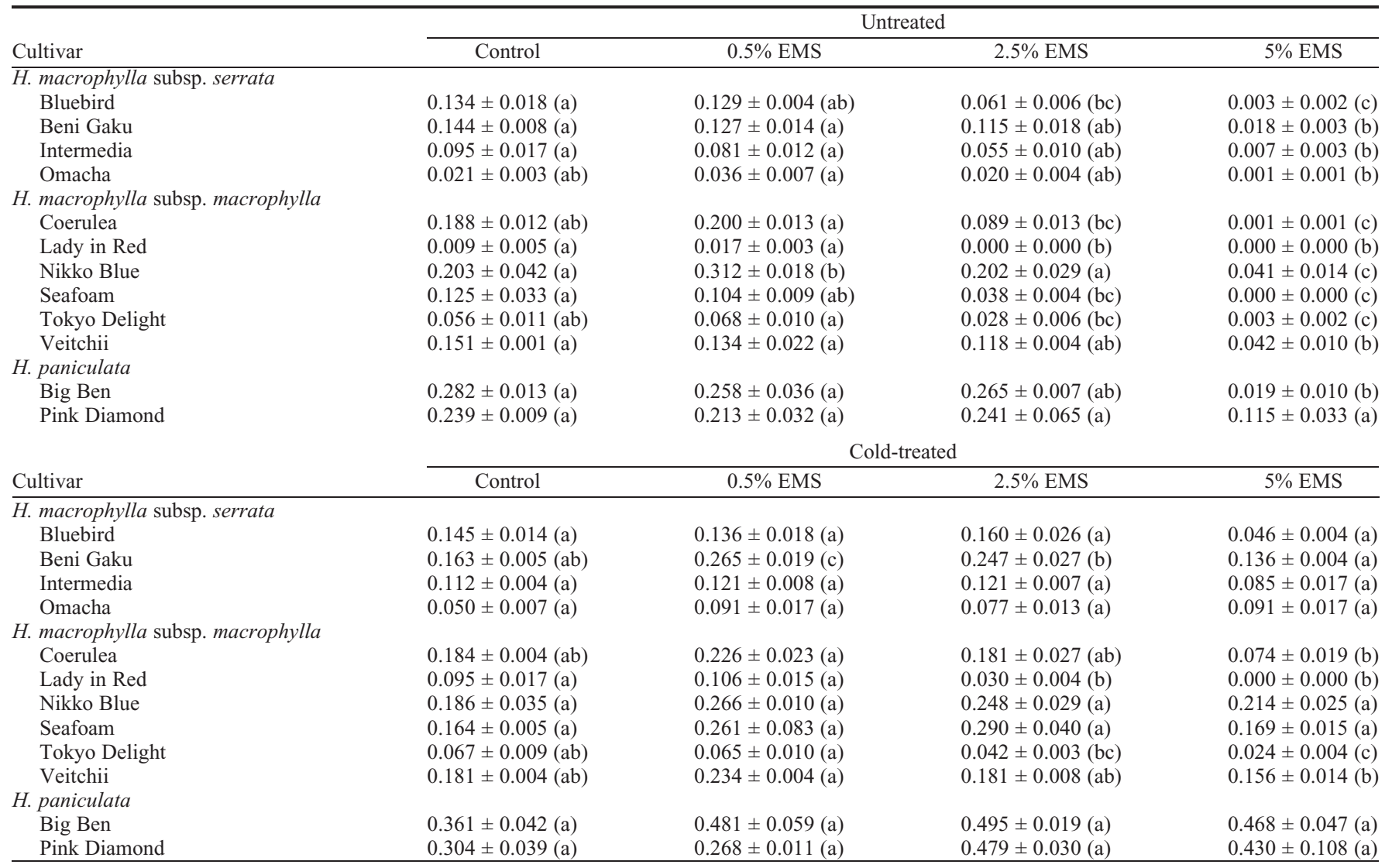

${ }^{\mathrm{z}}$ Results from untreated and cold-treated seed are grouped and treated separately. Calculated total germination for all seed (dormant and nondormant) within cultivar and treatment is reported as mean value $\pm \mathrm{SE}(\mathrm{n}=3)$. Letters in parentheses are the results of Ryan-Einot-Gabriel-Welsch Range post hoc analyses $(P<$ $0.05)$ from univariate analysis of variance $(\alpha=0.05)$ analyzing the range effects of dosage within cultivar. Thus, starting with the controls, different letters within row indicate that respective germination index values differ significantly as a result of EMS exposure.

higher concentrations of EMS are required to generate high mutation frequency. If cold treatment serves to force germination processes despite DNA damage, then the potential for greater numbers of mutants exists. Our estimation of M1 survival correlated highly with a seed's ability to germinate, even at the highest levels of EMS treatment (data not shown). M1 mutant phenotypes generated by our highest EMS concentrations were rare $(5 \%$ to $10 \%$, depending on cultivar) and mostly dwarf, variegated, or chlorotic. We are currently assaying the flowering and fertility of first-generation mutants. Our results suggest that chemical mutagenesis is an effective tool for random mutation breeding in Hydrangea. The demonstrated effectiveness of EMS and the parameters outlined for EMS mutagenesis should prove useful to hydrangea breeders seeking to increase allelic diversity and to geneticists seeking to understand gene function.

\section{Literature Cited}

Abramoff, M.D., P.J. Magelhaes, and S.J. Ram. 2004. Image processing with ImageJ. Biophotonics Intl. 11:36-42.

Alcantara, T.P., P.W. Bosland, and D.W. Smith. 1996. Ethyl methanesulfonate-induced seed mutagenesis of Capsicum annuиm. J. Hered. 87:239-241.

Britt, A.B. 1996. DNA damage and repair in plants. Annu. Rev. Plant Physiol. 47:75-100.
Dhamayanthi, K.P.M. and V.R.K. Reddy. 2002. Effect of mutagens on seed germination in Chilli (Capsicum annuum L.). J. Nucl. Agr. Biol. 31:47-53.

Filkowski, J., O. Kovalchuk, and I. Kovalchuk. 2004. Dissimilar mutation and recombination rates in Arabidopsis and tobacco. Plant Sci. 166:265-272.

Gamborg, O.L., R.A. Miller, and K. Ojima. 1968. Nutrient requirements of suspension cultures of soybean root cells. Exp. Cell Res. 50:151-158.

Grant, W.F. and E.T. Owens. 2001. Chromosome aberration assays in Pisum for the study of environmental mutagens. Mutat. Res.-Rev. Mutat. 488:93-118.

Greene, E.A., C.A. Codomo, N.E. Taylor, J.G. Henikoff, B.J. Till, S.H. Reynolds, L.C. Enns, C. Burtner, J.E. Johnson, A.R. Odden, L. Comai, and S. Henikoff. 2003. Spectrum of chemically induced mutations from a largescale reverse-genetic screen in Arabidopsis. Genetics 164:731-740.

Greer, S.P., S.M. Reed, J. Adkins, and T.A. Rinehart. 2008. Micropropagation and tissue culture of Hydrangea macrophylla for mutagenesis, ploidy manipulation, and possible transformation. HortScience 43:627. (abstr.).

Henikoff, S. and L. Comai. 2003. Single-nucleotide mutations for plant functional genomics. Annu. Rev. Plant Biol. 54:375-401.

Henikoff, S., B.J. Till, and L. Comai. 2004. TILLING. Traditional mutagenesis meets functional genomics. Plant Physiol. 135:630-636.

Hoffmann, G.R. 1980. Genetic effects of dimethyl sulfate, diethyl sulfate, and related compounds. Mutat. Res. 75:63-129.
Jabeen, N. and B. Mirza. 2002. Ethyl methane sulfonate enhances genetic variability in $\mathrm{Cap}$ sicum annuum. Asian J. Plant Sci. 1:425-428.

Jayakumar, S. and R. Selvaraj. 2003. Mutagenic effectiveness and efficiency of gamma rays and ethyl methane sulphonate in sunflower (Helianthus annuus L.). Madras Agr. J. 90:574 576.

Kimura, S. and K. Sakaguchi. 2006. DNA repair in plants. Chem. Rev. 106:753-766.

Lakon, G. 1949. The topographical tetrazolium method for determining the germinating capacity of seeds. Plant Physiol. 24:389-394.

McCallum, C.M., L. Comai, E.A. Greene, and S. Henikoff. 2000. Targeted screening for induced mutations. Nat. Biotechnol. 18:455-457.

Reed, S.M. 2000a. Compatibility studies in Hydrangea. J. Environm. Hort. 18:29-33.

Reed, S.M. 2000b. Development of an in ovolo embryo culture procedure for Hydrangea. J. Environm. Hort. 18:34-39.

Rinehart, T.A., B.E. Scheffler, and S.M. Reed. 2006. Genetic diversity estimates for the genus Hydrangea and development of a molecular key based on SSR. J. Amer. Soc. Hort. Sci. 131:787-797.

Sega, G.A. 1984. A review of the genetic effects of ethyl methanesulfonate. Mutat. Res. 134:113142.

Smith, F.G. 1952. The mechanism of the tetrazolium reaction in corn embryos. Plant Physiol. 27:445-456.

Sokal, R.R. and F.J. Rohlf. 1995. Biometry: The principles and practice of statistics in biological research. W.H. Freeman and Company, New York, NY. 
Till, B.J., S.H. Reynolds, E.A. Greene, C.A. Codomo, L.C. Enns, J.E. Johnson, C. Burtner, A.R. Odden, K. Young, N.E. Taylor, J.G. Henikoff, L. Comai, and S. Henikoff. 2003. Large-scale discovery of induced point mutations with high-throughput TILLING. Genome Res. 13:524-530.

Tukey, J.W. 1962. The future of data analysis. Ann. Math. Stat. 33:1-67.
Tuteja, N., M.B. Singh, M.K. Misra, P.L. Bhalla, and R. Tuteja. 2001. Molecular mechanisms of DNA damage and repair: Progress in plants. Crit. Rev. Biochem. Mol. 36:337-397.

van Harten, A.M. 1998. Mutation breeding: Theory and practical applications. Cambridge University Press, New York, NY.

Vonarx, E.J., H.L. Mitchell, R. Karthikeyan, I. Chatterjee, and B.A. Kunz. 1998. DNA repair in higher plants. Mutat. Res.-Fund. Mol. M. 400:187-200.

Waugh, R., D.J. Leader, N. McCallum, and D. Caldwell. 2006. Harvesting the potential of induced biological diversity. Trends Plant Sci. 11:71-79.

Xuebao, L. 1991. Effects of EMS on the germinating seeds of rice. J. Wuhan Bot. Res. 9:263267. 